2014-08

\title{
A note on the Krone deposition equation and significance of floc aggregation
}

Mehta, AJ

http://hdl.handle.net/10026.1/9469

10.1016/j.margeo.2014.04.002

Marine Geology

Elsevier BV

All content in PEARL is protected by copyright law. Author manuscripts are made available in accordance with publisher policies. Please cite only the published version using the details provided on the item record or document. In the absence of an open licence (e.g. Creative Commons), permissions for further reuse of content should be sought from the publisher or author. 
Provided for non-commercial research and education use. Not for reproduction, distribution or commercial use.

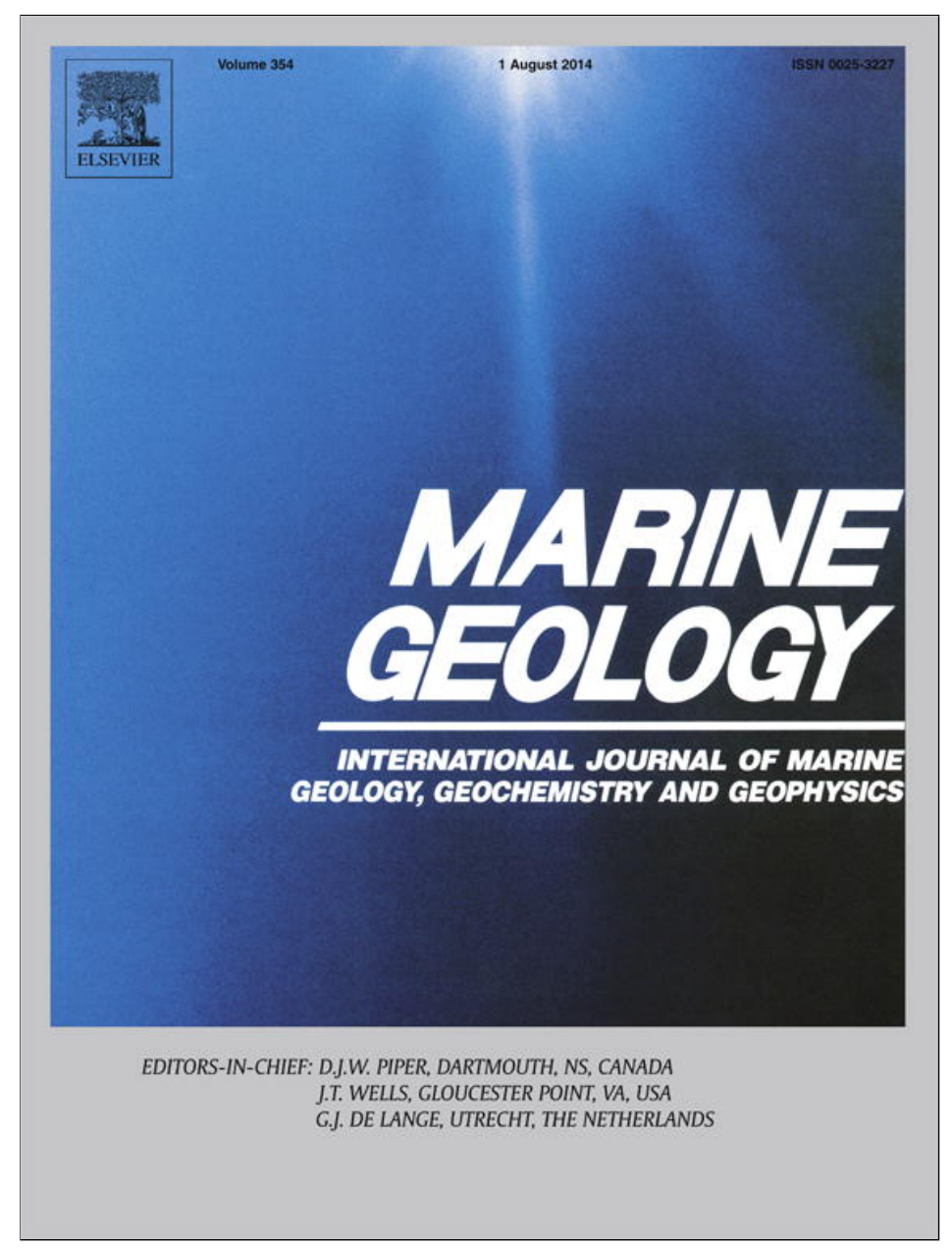

This article appeared in a journal published by Elsevier. The attached copy is furnished to the author for internal non-commercial research and education use, including for instruction at the authors institution and sharing with colleagues.

Other uses, including reproduction and distribution, or selling or licensing copies, or posting to personal, institutional or third party websites are prohibited.

In most cases authors are permitted to post their version of the article (e.g. in Word or Tex form) to their personal website or institutional repository. Authors requiring further information regarding Elsevier's archiving and manuscript policies are encouraged to visit:

http://www.elsevier.com/authorsrights 


\title{
A note on the Krone deposition equation and significance of floc aggregation
}

\author{
Ashish J. Mehta ${ }^{\mathrm{a}}$, Andrew J. Manning b,c,d,*, Yogesh P. Khare ${ }^{\mathrm{a}}$ \\ a College of Engineering, University of Florida, Gainesville, FL 32611, USA \\ ${ }^{\mathrm{b}}$ HR Wallingford, Howbery Park, Wallingford, Oxfordshire OX10 8BA, UK \\ ' School of Marine Science E Engineering, Plymouth University, Drake Circus, Plymouth, Devon PL4 8AA, UK \\ d Department of Geography, Environment and Earth Sciences, University of Hull, Hull HU6 7RX, UK
}

\section{A R T I C L E I N F O}

\section{Article history:}

Received 12 November 2013

Received in revised form 31 March 2014

Accepted 1 April 2014

Available online 12 April 2014

Communicated by J.T. Wells

\section{Keywords:}

cohesive sediment

estuaries

flocs

flow shear

San Francisco Bay

sedimentation

settling velocity

\begin{abstract}
A B S T R A C T
For modeling the rate of deposition of cohesive flocs in estuaries the Krone equation is extensively used. It was derived from flume experiments on muddy sediment from the San Francisco Bay, and is applicable to low suspended sediment concentration environments in which shear-induced aggregation - the growth and break up of flocs - has a limited role. It is shown that the use of this equation can lead to erroneous estimates of the mass deposition flux at typically higher estuarine concentrations. Krone's own experimental data permit the development of a more general equation accounting for the effects of concentration and turbulent shear rate on aggregation. These effects are dramatically observed in a deposition test in which a wire mesh was inserted in the flow to change the turbulent shearing rate and increase deposition. Even with the inclusion of aggregation effect in the general equation, field-based observations from San Francisco Bay suggest that typical flumes generally may not meet the space and time scaling requirements for field application of laboratory data. Thus, although the Krone equation should be eschewed in favor of the general equation, interpretations of model-predicted deposition rate must not be accepted without robust field-based verification.
\end{abstract}

(c) 2014 Elsevier B.V. All rights reserved.

\section{Introduction}

The transport of cohesive sediment flocs in estuaries is, in general, strongly influenced by turbulent shear-induced aggregation including the growth and breakup of flocs, which in turn determine the erosion and deposition mass fluxes (Winterwerp et al., 2006; Manning and Dyer, 2007; Soulsby et al., 2013). Since the characteristically diffused bed-water boundary at which these fluxes occur is difficult to model, a relatively new approach has been to treat the boundary as an interface internal to modeled domain (e.g. Le Hir, 1997; Hsu et al., 2003). However, such modeling remains complex and is the reason simple analytic equations continue to be used. Among these, the most well-known formula is the "Krone equation" reported by Krone (1962) and Einstein and Krone (1962) for the time-rate of change of the mass concentration of suspended flocs as a function of bed shear stress. Recent studies (e.g. Winterwerp, 2007) have pointed out that, when used under the assumption of constant floc diameter and density in the tidal environment, the Krone equation (in tandem with an erosion equation) produces physically questionable results with respect to predicted tidal variation of the suspended sediment concentration. Yet, in general,

\footnotetext{
* Corresponding author at: HR Wallingford, Howbery Park, Wallingford, Oxfordshire OX10 8BA, UK Fax: + 441491832233

E-mail address: andymanning@yahoo.com (A.J. Manning).
}

the equation remains a popular choice in fine sediment transport models (e.g. Martin and McCutcheon, 1998).

The Krone equation was derived for low concentrations of suspended sediment using mud from the San Francisco Bay in a laboratory flume with non-oscillatory flow. The concentration $C$ (dry mass per unit wet sample) can be conveniently expressed as solids volume fraction $\phi$, where $\phi=C / \rho_{s}$ and the material density $\rho_{s}$ is nominally equal to $2650 \mathrm{~kg} \mathrm{~m}^{-3}$. When $\phi$ is below a limiting value $\phi_{l}$, which is typically between $4 \times 10^{-5}$ and $1 \times 10^{-4}$ for the Bay sediment, aggregation by shear is slow because inter-particle collisions are infrequent. The floc diameter $d_{f}$ and the settling velocity $w_{s}$ are practically independent of $\phi$ as well as the shear rate $G$, i.e. the root-mean-square of the gradient in turbulent velocity fluctuations.

In estuaries including the San Francisco Bay, $\phi$ often exceeds $\phi_{l}$, either with tidal periodicity or under storm waves depending on the location, and aggregation becomes increasingly important with increasing $\phi$ (Manning and Schoellhamer, 2013). Since in general the floc diameter and the settling velocity depend on $\phi$ as well as $G$, the accuracy of changes in the time-rate and spatial pattern of shoaling predicted by the Krone equation becomes tenuous.

Unfortunately, the Krone equation is commonly used to predict deposition in the range $\phi_{l}<\phi<\phi_{h}$, where $\phi_{h} \approx 0.002-0.004$ is the upper limit of $\phi$ above which the rate of fall of particles is characteristically hindered by upward seepage of water in the settling slurry; see 


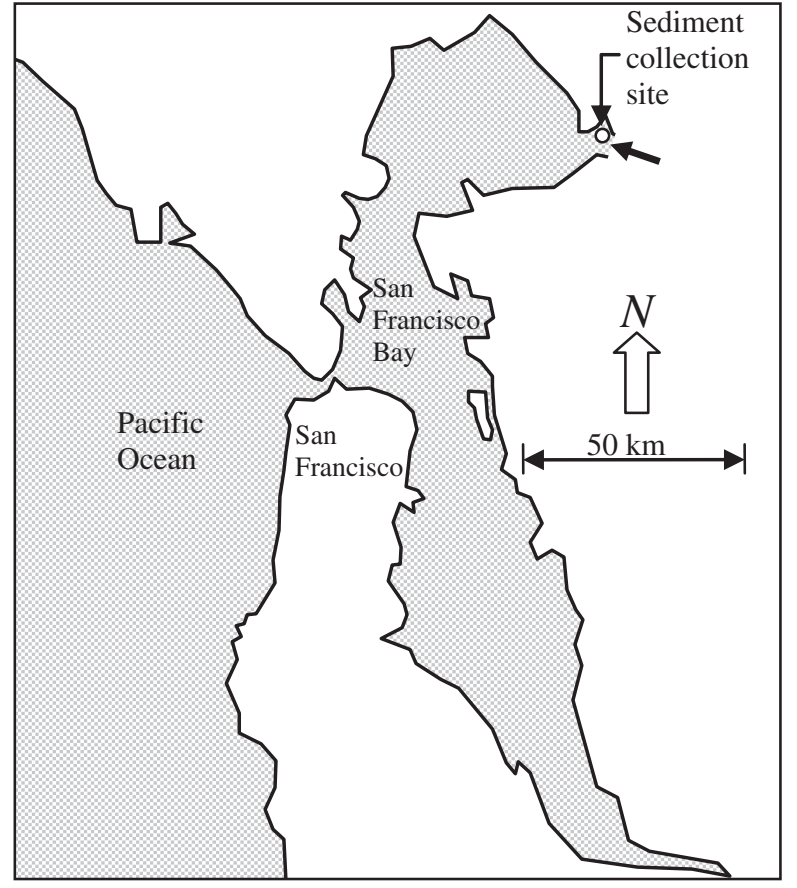

Fig. 1. The San Francisco Bay and Mare Island Strait sediment collection site. Thick arrow close to sediment collection site in studies of Krone (1962) and Mehta (1973) implies sediment inflow from river.

Winterwerp and van Kesteren (2004) for a discussion on the meaning of $\phi_{h}$. We argue that in place of using the Krone equation as a purely empirical construct at high solids volume fractions, a more accurate expression for deposition must be employed. Such an expression, accounting the effects of $\phi$ and $G$ on settling floc properties, is readily obtained by relying on Krone's own experiments with the Bay sediment as shown previously by Shrestha and Orlob (1996).

\section{Flume experiments}

Bay mud collected from Mare Island Strait in the northwestern part of the estuary (Fig. 1) was tested in a $30 \mathrm{~m}$ long and $0.9 \mathrm{~m}$ wide flume with a flow-return pipe and a pump to recirculate saltwater and sediment. The water depth $h$ was kept at $0.3 \mathrm{~m}$. After fully mixing sediment and water (at salinity $S=17 \%$ ond nominal density $\rho_{w}=1025 \mathrm{~kg} \mathrm{~m}^{-3}$ ) at a high flow velocity $u_{m}$, the velocity was reduced and held constant at $0.107 \mathrm{~m}$ $\mathrm{s}^{-1}$ (Table 1). Suspended sediment concentration $C$ taken as the depthmean value was measured using both an optical sensor and gravimetric analysis of samples of suspension withdrawn at specific times.

In addition to five deposition test runs at different flow velocities and initial concentrations, a separate deposition test was carried out in the same flume but at a slightly lower salinity $(S=15 \%)$. In this test the significance of aggregation was qualitatively revealed by mechanically changing flow turbulence. To do so an industrial metallic grid (of

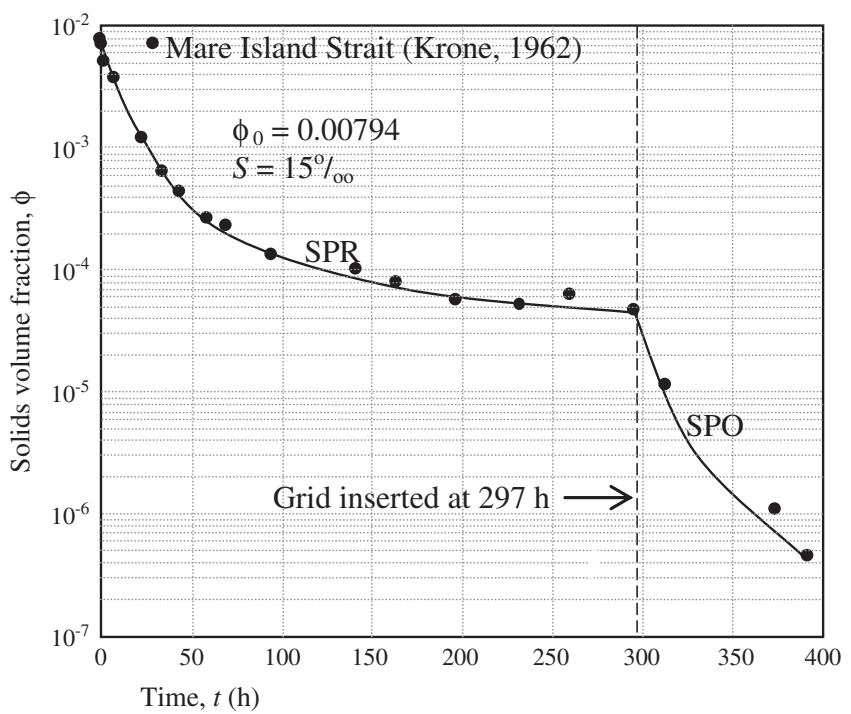

Fig. 2. Variation of solids volume fraction with time in grid insertion test of Krone (1962). Lines indicate mean trends.

unreported opening) was inserted across the flow area close to the flume head, thus producing a drastic increase in the rate of deposition downstream. More recent grid insertion experiments using sand have provided confirmatory data on the increase in turbulent intensity downstream of the grid (e.g. Sumer et al., 2003).

In Fig. 2, the solids volume fraction $\phi$ is plotted against time $(t)$ starting with the initial solids volume fraction $\phi_{0}=0.008$. At this high value settling was hindered until $\phi$ was below about 0.004 (Krone, 1962). Given mass settling flux $F_{s}=\rho_{s} w_{s} \phi$, in the first phase (SPR) of the test, $\phi$ decreased rapidly at first in spite of hindrance to settling, with $F_{s}=0.72 \mathrm{~kg} \mathrm{~m}^{-2} \mathrm{~h}^{-1}$ representing the initial rate of deposition. The flux then decreased gradually and reached a small value of about $0.0014 \mathrm{~kg} \mathrm{~m}^{-2} \mathrm{~h}^{-1}$ just before the grid was inserted at $297 \mathrm{~h}$. This increased $F_{S}$ in the second phase (SPO) due to aggregation by nearly an order of magnitude to $0.030 \mathrm{~kg} \mathrm{~m}^{-2} \mathrm{~h}^{-1}$. The test was terminated at $392 \mathrm{~h}$, when $F_{s}$ had reduced to a negligible $0.0004 \mathrm{~kg} \mathrm{~m}^{-2} \mathrm{~h}^{-1}$.

\section{Deposition rate equation}

The effect of aggregation on the settling flux $F_{s}$ is deduced from particle balance. The rate of change of the instantaneous floc diameter $d_{f}(t)$ is equated to the difference between the rates of floc growth $r_{g}$ and break up $r_{b}$ with respect to the number concentration of particles (e.g. Overbeek, 1952):

$\frac{d d_{f}}{d t}=r_{g}-r_{b}$.

Inter-particle encounters leading to floc growth are promoted by diffusion associated with small fluid eddies and, as a result, for a floc of

Table 1

Sediment properties.

\begin{tabular}{|c|c|c|c|c|}
\hline Test & Source & Fluid & $\phi_{0}(-)$ & $\begin{array}{l}\tau_{d} \\
(\mathrm{~Pa})\end{array}$ \\
\hline SR & Mare Island Strait, California & Saltwater $(S=17 \%$ o) & $1.72 \times 10^{-4}-3.28 \times 10^{-3}$ & 0.081 \\
\hline SC & Mare Island Strait, California & Native water + water with $S \approx 5 \%$ NaCl & $2.72 \times 10^{-4}$ & 0.065 \\
\hline MM & Maracaibo estuary, Venezuela & Native water + water with $S \approx 5 \%$ NaCl & $7.88 \times 10^{-4}-1.03 \times 10^{-3}$ & 0.150 \\
\hline KD & Mined kaolinite, Florida & Distilled water & $4.00 \times 10^{-4}-3.64 \times 10^{-3}$ & 0.180 \\
\hline KS & Mined kaolinite, Florida & Saltwater $(S \approx 5 \% \circ \mathrm{NaCl})$ & $2.32 \times 10^{-3}-3.88 \times 10^{-3}$ & 0.150 \\
\hline SPR & Mare Island Strait, California & Saltwater $(S=15 \%)$ & $3.73 \times 10^{-3}$ & 0.081 \\
\hline SPO & Mare Island Strait, California & Saltwater $(S=15 \%)$ & $1.11 \times 10^{-4}$ & 0.081 \\
\hline
\end{tabular}


given diameter, $r_{g}$ is found to vary with $\phi$ and $G$. Since breakup occurs when the local fluid shear stress exceeds the floc shear strength, $r_{b}$ depends on $G$ only. Son and Hsu (2008) proposed expressions for $r_{g}$ and $r_{b}$ relevant to cohesive mineral flocs assumed to have fractal self-similarity characterized by the linear dimension $D$ (e.g. Chen and Eisma, 1995). In this idealization, any floc of diameter $d_{f}$ is constructed from basic particulate "building blocks" of primary particle diameter $d_{p}$. From sensitivity analysis it was shown that the resulting expressions for $r_{g}$ and $r_{b}$ are reduced to simpler forms used by Winterwerp (1998).

We will consider that shear-induced diffusion is dependent on $\phi^{m(G)}$ where the exponent $m$ can vary with $G$. By selecting $D=2$ as a nominal value for estuarine flocs including those in the San Francisco Bay (Winterwerp and van Kesteren, 2004), Eq. (1) can be shown to result in

$\frac{d d_{f}}{d t}=\left[k_{g} \rho_{s} \phi^{m(G)} G d_{f}^{2}-k_{b} \sqrt{G} d_{f}^{2}\left(d_{f}-d_{p}\right)\right] G$

where $k_{g}$ and $k_{b}$ are sediment dependent growth and breakup coefficients, respectively. This balance reduces to that of Winterwerp (1998) when $m(G)=1$. When $r_{g}$ and $r_{b}$ become equal at equilibrium $\left(d d_{f} / d t=0\right)$ the diameter is

$d_{f e}=\frac{k_{g}}{k_{b}} \frac{\rho_{s}}{\sqrt{G}} \phi^{m(G)}$

where we have assumed that $d_{p} / d_{f e}<<1$, which is typical. We will also assume the applicability of Stokes law for the settling velocity of equilibrium-diameter flocs

$w_{s}=\frac{g \Delta \rho_{f}}{18 \eta} d_{f e}^{2}$

where $\Delta \rho_{f}=\rho_{f}-\rho_{w}, \rho_{f}$ is the floc density, $\eta$ is the dynamic viscosity of the carrier fluid (water) and $g$ is the acceleration due to gravity. For flocs conforming to fractal self-similarity

$\Delta \rho_{f}=\Delta \rho_{s}\left(\frac{d_{f e}}{d_{p}}\right)^{\alpha(D-3)}$

where $\Delta \rho_{s}=\rho_{s}-\rho_{w}$ and $\alpha$ empirically accounts for the effect of multisize primary particles (building blocks) of cohesive minerals (Khelifa and Hill, 2006). Eq. (5) is used to determine $D$ when $\alpha=1$ (Kranenburg, 1994). Setting $D=2$ and combining Eqs. (3), (4) and (5) we obtain

$w_{s}=a(G) \phi^{n(G)}$

where

$a(G)=\frac{g \rho_{s}^{2-\alpha} d_{p}^{\alpha} \Delta \rho_{s}}{18 \eta}\left(\frac{k_{g}}{k_{b}}\right)^{2-\alpha} G^{\frac{\alpha}{2}-1} ; \quad n(G)=(2-\alpha) m(G)$.

Eq. (6) was derived empirically by Krone (1962) with values of $a$ and $n$ independent of $G$ deduced mainly from settling tests on the Bay mud flocs in a glass cylinder. It was shown that this equation was consistent with the kinetics of inter-particle collisions and aggregation during the settling of suspended flocs previously postulated by Overbeek (1952).

For the deposition of flocs of uniform size in steady flow, $\phi(t)$ is obtained from sediment mass balance

$h \frac{d \phi}{d t}=-\left(1-\frac{\tau_{b}}{\tau_{d}}\right) \frac{F_{s}}{\rho_{s}}=-\left(1-\frac{\tau_{b}}{\tau_{d}}\right) w_{s} \phi$

where $\tau_{b}$ is the bed shear stress and $\tau_{d}$ is the deposition shear stress, a characteristic quantity (Krone, 1962). When $\tau_{b}$ is less than $\tau_{d}$ all initially suspended sediment eventually settles out, while at higher values of $\tau_{b}$ no sediment is able to deposit. Combining Eqs. (6) to (8) yields

$\frac{d \phi}{d t}=-\frac{a(G)}{h}\left(1-\frac{\tau_{b}}{\tau_{d}}\right) \phi^{n(G)+1}$.

The Krone equation is obtained by taking $w_{s}$ in Eq. (6) to be constant, i.e. independent of $\phi$, which reduces Eq. (9) reduces to

$\frac{d \phi}{d t}=-\frac{w_{s}}{h}\left(1-\frac{\tau_{b}}{\tau_{d}}\right) \phi$

Given the initial solids volume fraction $\phi_{0}\left(<\phi_{h}\right)$, integration results in

$\phi *(t)=e^{-\frac{w_{s}}{h}\left(1-\frac{\tau_{b}}{\tau_{d}}\right) t}$

where $\phi^{*}(t)=\phi(t) / \phi_{0}$ is the normalized value of $\phi$. Eq. (11) predicts exponential decrease in $\phi^{*}(t)$, which is consistent with the deposition data of Krone (1962) and Mehta (1973) for the Bay mud and other cohesive sediments when $\phi<\phi_{l}$ which is typically not greater than 0.0001 .

The general solution of Eq. (9)

$\phi *(t)=\left[1+\frac{a(G) n(G) \phi_{0}^{n(G)}}{h}\left(1-\frac{\tau_{b}}{\tau_{d}}\right) t\right]^{-\frac{1}{n(G)}}$.

As we will see later, for large values of $t$ the trend of Eq. (12) approaches that of Eq. (11).

With regard to the measurements and Eq. (12) in Fig. 3 for the Bay sediment, $\phi_{0}$ for each run is given in Table 1 . As for $\tau_{d}, 0.081 \mathrm{~Pa}$ appears to provide reasonable fit for the Krone (1962) runs (SR, SPR and SPO), although based on Eq. (11) fit the value reported by Krone (1962) was $0.060 \mathrm{~Pa}$. For SC, the reported value of $0.065 \mathrm{~Pa}$ (Mehta, 1973) is reasonably close to $0.060 \mathrm{~Pa}$. Similar to Shrestha and Orlob (1996), the openchannel turbulent shear rate $G$ was estimated from

$G=\frac{30 \sqrt{K} u_{m}}{\kappa \sqrt{\rho_{w}} h}=\frac{30 \sqrt{\tau_{b}} u_{m}^{0.03}}{\kappa \sqrt{\rho_{w}} h}$

where $K=g \rho_{w} n_{f}^{2} / h^{1 / 3} n_{f}(=0.013)$ is Manning's bed resistance coefficient and $\kappa$ is the Karman constant $(=0.40)$. Also following Shrestha and Orlob (1996), $G$ was evaluated at the near-bed depth of $h / 30$ where aggregation can be expected to be significant due to high shear.

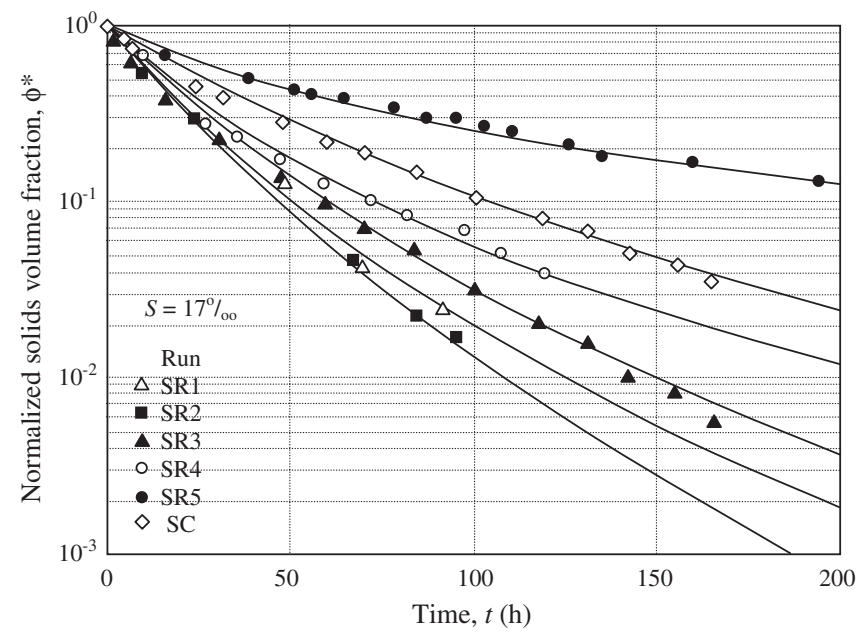

Fig. 3. Variation of normalized solids volume fraction with time for the Bay sediment deposition. Lines are from Eq. (12). 
The bed shear stress $\tau_{b}$ was evaluated from the Krone (1962) flume study as

$\tau_{b}=K u_{m}^{1.94}$

in which the exponent 1.94 is close to the 2 indicating the quadratic law of bed resistance in turbulent flow.

In Fig. 3, the variability in the rate of change of $\phi^{*}$ reflects the dependence of rate of change of $\phi$ on the initial solids volume fraction $\phi_{0}$ and $\tau_{b}$ (Table 2). These two quantities together represent the effect of aggregation on settling flocs. Included also in Fig. 3 is a single test (SC) using the Bay sediment from the same site in a counter-rotating annular flume (CRAF). The principle and working of this generally well-known apparatus as well as representative deposition data are found in Mehta and Partheniades (1975). Best-fit values of $a$ and $n$ are given in Table 2 for SR and SC. Both coefficients generally increase with $G$ signifying increasing settling velocity with $G$. Overall, this effect can be represented by the half-time $t_{50}$ at which $\phi^{*}$ decreases to 0.5 . From Eq. (12)

$t_{50}=\frac{2^{n}-1}{\frac{a n \phi_{0}^{n}}{h}\left(1-\frac{\tau_{b}}{\tau_{d}}\right)}$.

In Fig. 4, values $t_{50}$ calculated from Eq. (15) are plotted against $G$ (varied arbitrarily from 0.5 to $3.5 \mathrm{~s}^{-1}$ ) for SR and SC. Measured $t_{50}$ from the CRAF have also been included for sediments MM (mud from the Maracaibo estuary in Venezuela), KD (dry kaolinite mixed in distilled water) and KS (kaolinite in saltwater) reported by Mehta and Partheniades (1975). Taking $G=1 \mathrm{~s}^{-1}$ as a representative shear rate, the Bay mud (SR and SC) took the longest to settle with $t_{50}=14.2 \mathrm{~h}$ compared to $0.4 \mathrm{~h}$ for the Maracaibo mud (MM), and $0.07 \mathrm{~h} \mathrm{(4.2} \mathrm{min)}$ for kaolinite (KD and KS). KD and KS had two different types of flocs due to sodium and chloride ions from $\mathrm{NaCl}$ (salt) added to KS. Representation of the mean trends for both sediments by a single line may indicate insufficient data points necessary to resolve individual trends.

A noteworthy observation is the seeming agreement between the trend of SC with that of SR, suggesting that both - Krone's flume with high shear in the return-flow pump and the CRAF without a flocdisrupting pump - produced flocs that settled at comparable rates. This may mean that in Krone's flume flocs disrupted in the return flow pipe were rapidly re-aggregated as they reentered the flume. It could also mean that in the CRAF, the characteristically complex turbulent flow structure limited floc growth (Schweim et al., 2000; McAnally and Mehta, 2002).

\section{Significance of aggregation}

\subsection{Initial concentration effect}

The significance of aggregation on the settling flux is illustrated by Fig. 5 in which $F_{s}=a(G) \rho_{s} \phi^{n(G)}+1$ obtained from the SPR data (Fig. 2) is fitted with the general Eq. (12), along with all 10 points

Table 2

The Bay sediment test parameters.

\begin{tabular}{llllllll}
\hline Run & $\begin{array}{l}u_{m} \\
\left(\mathrm{~m} \mathrm{~s}^{-1}\right)\end{array}$ & $\begin{array}{l}C_{0} \\
\left(\mathrm{~kg} \mathrm{~m}^{-3}\right)\end{array}$ & $\begin{array}{l}\phi_{0} \\
(-)\end{array}$ & $\begin{array}{l}\tau_{b} \\
(\mathrm{~Pa})\end{array}$ & $\begin{array}{l}G \\
\left(\mathrm{~s}^{-1}\right)\end{array}$ & $\begin{array}{l}a(G) \\
\left(\mathrm{m} \mathrm{s}^{-1}\right)\end{array}$ & $\begin{array}{l}n(G) \\
(-)\end{array}$ \\
\hline SR1 & 0.061 & 0.46 & $1.72 \times 10^{-4}$ & 0.011 & 0.75 & 0.080 & 0.165 \\
SR2 & 0.076 & 0.98 & $3.72 \times 10^{-4}$ & 0.017 & 0.93 & 0.050 & 0.110 \\
SR3 & 0.122 & 6.29 & $2.37 \times 10^{-3}$ & 0.041 & 1.49 & 0.080 & 0.170 \\
SR4 & 0.134 & 8.69 & $3.28 \times 10^{-3}$ & 0.050 & 1.64 & 0.200 & 0.300 \\
SR5 & 0.165 & 3.54 & $1.34 \times 10^{-3}$ & 0.074 & 2.01 & 5.500 & 0.650 \\
SC & 0.114 & 0.72 & $2.72 \times 10^{-4}$ & 0.036 & 1.39 & 0.095 & 0.220 \\
SPR & 0.107 & 9.89 & $3.73 \times 10^{-3}$ & 0.032 & 1.30 & 4.3 & 0.73 \\
SPO & 0.107 & 0.295 & $1.11 \times 10^{-4}$ & 0.032 & - & 4 & 0.405 \\
\hline
\end{tabular}

a Excluding first six data points representing hindered settling.

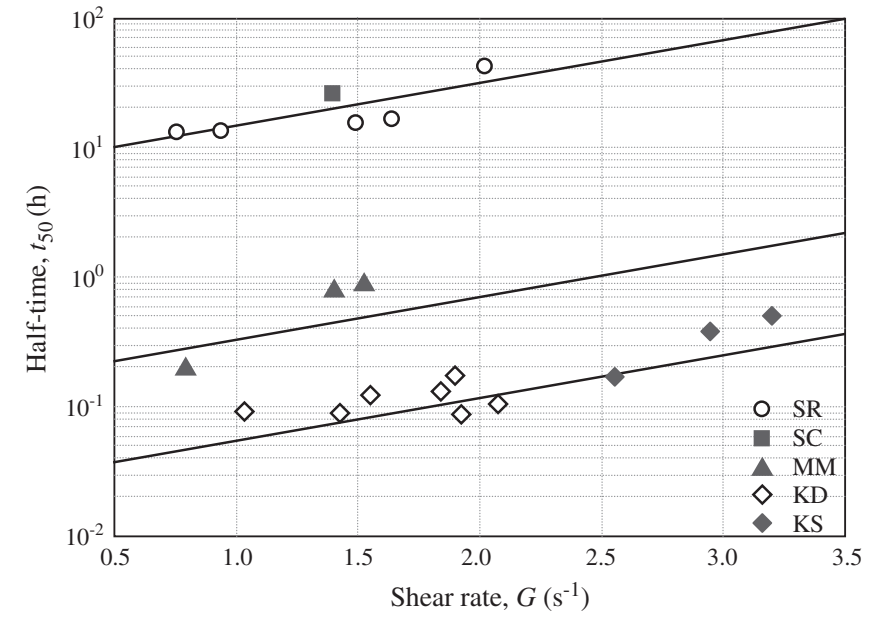

Fig. 4. Variation of half-time with shear rate from different experiments. Lines are meant to suggest mean trends.

from data on $\phi$. The line corresponding to the Krone Eq. (11) is based on the lowest 6 values of $\phi$. This yielded $\phi_{0}=0.11$ as the best-fit extrapolated value, and the respective coefficient of the exponent $w_{s}\left[1-\left(\tau_{\mathrm{b}} /\right.\right.$ $\left.\left.\tau_{\mathrm{d}}\right)\right] / h=0.011$. As expected the two models agree reasonably well at fluxes less than about $23.5 \mathrm{~kg} \mathrm{~m}^{-2} \mathrm{~h}^{-1}$ (at times greater than $67 \mathrm{~h}$ ), consistent with the exponential behavior of Eq. (11). At times less than $67 \mathrm{~h}$ the extrapolated (dashed line in Fig. 5) curve under-predicts the flux. Taking $200 \mathrm{~h}$ as convenient total test duration, deposition calculated from Eq. (12) would be $5587 \mathrm{~kg} \mathrm{~m}^{-2}$ and, from Eq. (11), $3823 \mathrm{~kg} \mathrm{~m}^{-2}$. The reduction of $1764 \mathrm{~kg} \mathrm{~m}^{-2}$, i.e. about $46 \%$ of the Eq. (11) flux, is almost entirely due to the anomaly between the two equations during the first $67 \mathrm{~h}$. At $200 \mathrm{~h}$ the anomaly is $4.81 \mathrm{~kg} \mathrm{~m}^{-2}$, a minor quantity.

The initial concentration $C_{0}$ following the initial phase of hindered settling is taken as $9.89 \mathrm{~kg} \mathrm{~m}^{-3}\left(\phi_{0}=3.73 \times 10^{-3}\right.$; Table 2$)$, an unusually high depth-mean value in the San Francisco Bay, although common in many estuaries. For a lower $C_{0}$ the initial anomaly would be much smaller but may not be insignificant. This is evident in an approximate way assuming that the initial time is $30 \mathrm{~h}$ later, i.e. when $\phi(30 \mathrm{~h})=\phi_{0}=$ $5.2 \times 10^{-4}$, or $C_{0}=1.38 \mathrm{~kg} \mathrm{~m}^{-3}$, a more realistic value for the Bay. At that instant the Krone equation deposition flux of $30 \mathrm{~kg} \mathrm{~m}^{-2} \mathrm{~h}^{-1}$ based on Eq. (11) would be about one-third lower than the more accurate value from Eq. (12).

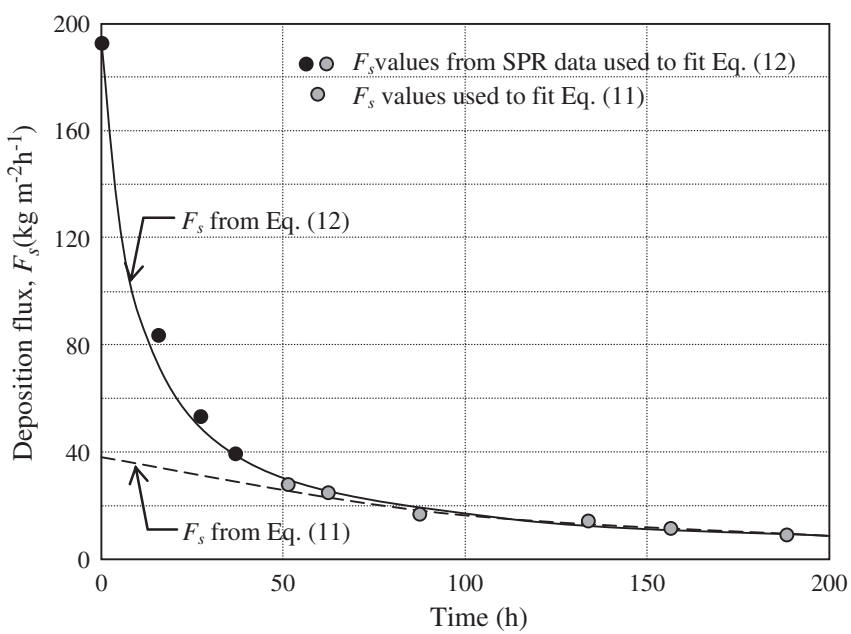

Fig. 5. Variation of deposition flux with time from SPR data (Fig. 2), Eqs. (11) and (12). 


\subsection{Shear rate effect}

The pre-grid (SPR) and post-grid (SPO) deposition curves in Fig. 2 can be roughly compared by assuming that although the grid likely changed $G$, the bed shear stress $\tau_{b}$ remained practically unaffected (Table 2 ) as the flow velocity did not change measurably. The effect of change in $G$ would manifest in the post-grid values of $a(G)$ and $n(G)$ in Eq. (12). One would expect that the grid was the main cause of change. Up to unquantifiable but possibly minor extent, $a(G)$ and $n(G)$ may also have been influenced by differences in suspended sediment properties at the start $(t=0)$ of SPR and at the start of SPO $(t=297 \mathrm{~h})$.

In Fig. 6, Eq. (12) best-fitted to SPR and SPO reveals a significant effect of the grid on the deposition flux, for which we may consider the settling velocity $w_{s}$ and the corresponding floc diameter $d_{f}$ as convenient proxies. Let $10^{-1} \mathrm{~kg} \mathrm{~m}^{-3}\left(\phi=3.77 \times 10^{-5}\right)$ be the representative (order of magnitude) mean concentration in the Bay (Manning and Schoellhamer, 2013) and $\Delta \rho_{f}=174 \mathrm{~kg} \mathrm{~m}^{-3}$ the respective excess floc density (Krone, 1963). Thus we can calculate $w_{s}$ from Eq. (6), then $d_{f}$ from Eq. (4), and the particle-based Reynolds number as Re $=\rho_{w} d_{f} w_{s} / \eta$ with $\rho_{w}=1025 \mathrm{~kg} \mathrm{~m}^{-3}$ and $\eta=0.00115 \mathrm{~Pa} \cdot \mathrm{s}$ (Table 3). Referring to Table 3, in SR, SC and SPR the overall range of diameters was 3.3 to $8.5 \mu \mathrm{m}$, and in SPO the diameter increased to $16.9 \mu \mathrm{m}$. The respective range of $w_{s}$ in SR, SC and SPR was $7.05 \times 10^{-7}$ to $4.53 \times 10^{-6} \mathrm{~m} \mathrm{~s}^{-1}$. This range closely matches the range believed to be necessary to maintain equilibrium over a neap-spring cycle in the estuary (Prandle et al., 2005). In SPO, $w_{s}$ increased to $1.80 \times 10^{-5} \mathrm{~m} \mathrm{~s}^{-1}$ indicating an orderof-magnitude jump in the rate of fall of particles. The increase in Reynolds number was remarkably three orders-of-magnitude, from 2.10 indicating almost no turbulence during SPR, to 270 during SPO signifying weak turbulence. In other words, enhancement of turbulence due to the grid was highly conducive to floc growth.

\section{Concluding discussion}

The most important contribution of the Krone (1962) study was a physics-based framework for understanding and organizing cohesive sediment deposition data. This is evident from numerous subsequent estuarine investigations of the settling behavior of flocs (e.g. Winterwerp and van Kesteren, 2004).

A limitation of typical flume studies can be highlighted by a comparison of the relationship between $\Delta \rho_{f}$ and $d_{f}$ obtained in the laboratory with data derived from the field by in situ optical or acoustic devices. In Fig. 7, domains defined by these two variables are shown based on field-based observations of Kranck and Milligan (1992), Letter (2009) and Manning and Schoellhamer (2013). Notwithstanding differences

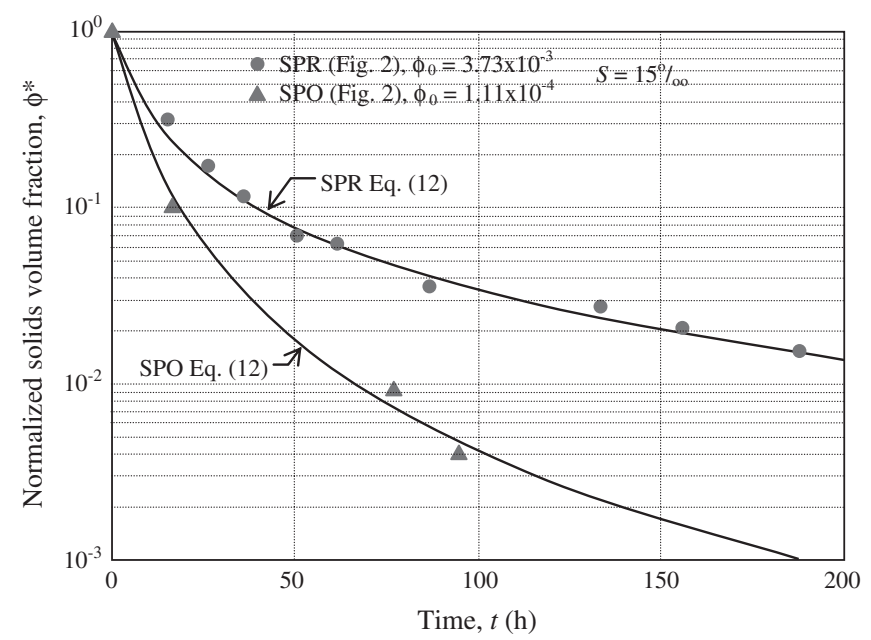

Fig. 6. Effect of changing shear rate on the deposition of the Bay sediment.
Table 3

Characteristic settling velocities, diameters and Reynolds numbers.

\begin{tabular}{llcc}
\hline Run & $\begin{array}{l}w_{s} \\
\left(\mathrm{~m} \mathrm{~s}^{-1}\right)\end{array}$ & $\begin{array}{l}d_{f} \\
(\mu \mathrm{m})\end{array}$ & $\operatorname{Re}=\frac{\rho_{w} d_{f} w_{s}}{\eta}$ \\
\hline SR1 & $4.14 \times 10^{-6}$ & 8.1 & 29.9 \\
SR2 & $4.53 \times 10^{-6}$ & 8.5 & 34.2 \\
SR3 & $3.93 \times 10^{-6}$ & 7.9 & 27.7 \\
SR4 & $2.62 \times 10^{-6}$ & 6.4 & 15.0 \\
SR5 & $2.04 \times 10^{-6}$ & 5.7 & 10.3 \\
SC & $2.81 \times 10^{-6}$ & 6.7 & 16.7 \\
SPR & $7.05 \times 10^{-7}$ & 3.3 & 2.10 \\
SPO & $1.80 \times 10^{-5}$ & 16.9 & 270 \\
\hline
\end{tabular}

in the methods of measurement, the observed variability in the domains can be attributed to differences in the locations of measurement, seasonality and the fact that data collections were carried out at different times and over nearly three decades. During this period sediment redistribution likely occurred within the large bay along with influx of new sediment from the river system (arrow in Fig. 1). Such a long-term trend was previously documented by Krone (1979).

Rheometric measurements were carried out by Krone (1963) in a rotational viscometer in which the Bay mud sample was subjected to shear rates $G$ equivalent to the range in flume deposition tests. Calculation of $\Delta \rho_{f}$ was based on the assumption of discrete floc structures or "orders of aggregation" that occurred sequentially as $G$ was first increased in steps, then decreased in the reverse order. This resulted in $\Delta \rho_{f}$ values ranging between 79 and $269 \mathrm{~kg} \mathrm{~m}^{-3}$ encompassing six orders of aggregation.

Due to the assumption of self-similarity among orders of aggregation based on the floc void ratio rather than diameter, Krone (1962) could not establish a fractals-based relationship between $\Delta \rho_{f}$ and $d_{f}$. Nonetheless, it was inferred that with $d_{f}$ increasing due to aggregation $\Delta \rho_{f}$ decreases, and as a result large Bay flocs are loosely bound and lighter compared to smaller, tightly-packed units. This is amply borne out by the general nature of mean trends from the field investigations in Fig. 7. The excess density decreases rapidly with increasing diameter, a seemingly ubiquitous behavior in estuaries examined in some detail by Khelifa and Hill (2006). Their analysis also indicated that as flocs become larger they acquire increasingly two-dimensional structures represented by decreasing fractal dimension. For simplicity of treatment this variability in $D$ is not considered in the derivation of depositionrate Eqs. (9) or (10).

In Fig. $7, d_{f}$ ranges corresponding to $\Delta \rho_{f}$ limits of 79 and $269 \mathrm{~kg} \mathrm{~m}^{-3}$ (Krone, 1963) have been obtained from Eqs. (4) and (6). Values of $d_{f}$ in Table 3 are for the mean density of $174 \mathrm{~kg} \mathrm{~m}^{-3}$ only. The laboratory

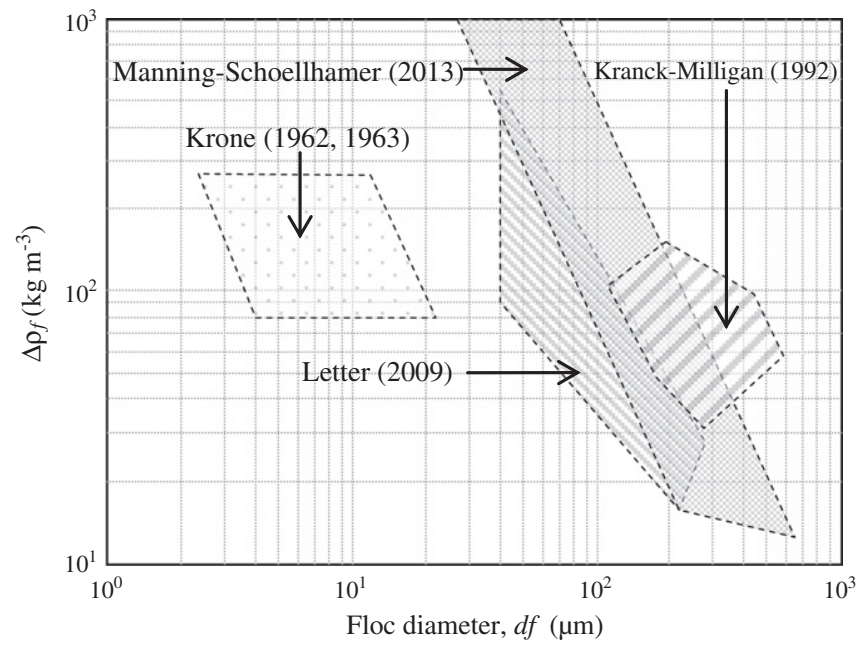

Fig. 7. Variation of excess floc density with diameter for the Bay mud. Areas identified by dashed boundaries represent approximate limits of respective data points. 
diameters are smaller than field-based values by at least an order of magnitude. Since the Bay sediment deposition behavior in the CRAF was consistent with the Krone flume and the flocs were in suspension for tens of hours in both apparatuses, we may infer that the scale of turbulence as well as lack of adequate time for growth in the confined environment were leading factors governing floc size in the laboratory visà-vis the Bay.

Without resorting to a formal analysis of floc sizes based on the Kolmogorov (1941) scale (e.g. Fugate and Friedrichs, 2003), we note that in shallow estuaries such as the San Francisco Bay (depths on the order of $3 \mathrm{~m}$ ) and in flumes (depth $0.3 \mathrm{~m}$ ), the depth ratio of 10 can be considered to be a proxy for the boundary-layer eddy scale. A noteworthy consequence of small eddies in flumes is that shear rates tend to be only on the order of $1 \mathrm{~s}^{-1}$, which can promote net growth but not net breakup. This constraint may not be realistic inasmuch as an order-of-magnitude greater $G$ values have been reported in the Bay (Manning and Schoellhamer, 2013).

The Krone deposition equation [Eqs. (9) or (11)] is unsuitable as a generic formula due to its potential for severely under-predicting the deposition flux. The more general Eqs. (10) or (12) is far more preferable in that regard, as long as it is recognized that it is based on experimental work in which model-to-prototype scaling limitations related to floc aggregation could not be overcome. Thus there is a strong case for in situ measurements of settling velocity leading to values of $a$ and $n$ in Eq. (12). The laboratory-based values of $\tau_{d}$ in Table 1 appear to be close to each other relative to the typical range of bed shear stress in estuaries. The use of these or similar values may be adequate for a firstorder estimation of deposition rate in the field. A more precise approach would be to deduce the best value of $\tau_{d}$ by calibrating Eq. (12) against measured shoaling rates in the field.

\section{Acknowledgments}

Professor Manning's contribution to the preparation of this paper was partly funded by both the US Geological Survey Co-operative Agreement Award (G11AC20352) with HR Wallingford (DDS0280), and the HR Wallingford Company Research 'Sediment in Transitional Environments - SiTE' project (DDY0427). Professor Manning would like to thank his HR Wallingford Coasts \& Estuaries colleagues Prof. Richard Whitehouse and Tim Chesher, for their continued support.

\section{References}

Chen, S., Eisma, D., 1995. Fractal geometry of in-situ flocs in the estuarine and coastal environments. Netherlands Journal of Sea Research 32, 173-182.

Einstein, H.A., Krone, R.B., 1962. Experiments to determine modes of cohesive sediment transport in salt water. Journal of Geophysical Research 67, 1451-1461.

Fugate, D.C., Friedrichs, C.T., 2003. Controls on suspended aggregate size in partially mixed estuaries. Estuarine, Coastal and Shelf Science 58, 389-404.

Hsu, T.-J., Jenkins, J.T., Liu, P.L.-F., 2003. On two-phase sediment transport: dilute flow. Journal of Geophysical Research 108 (C3), 3057. http://dx.doi.org/10.1029/ 2001JC001276.
Khelifa, A., Hill, P.S., 2006. Models for effective density and settling velocity of flocs. Journal of Hydraulic Research 44 (3), 390-401.

Kolmogorov, A.N., 1941. The local structure of turbulence in incompressible viscous fluid for very large Reynolds numbers. Comptes Rendus de l'Académie des Sciences URSS 30, 301.Dissipation of energy in locally isotropic turbulence. Comptes Rendus de l'Académie des Sciences URSS, 32, 16

Kranck, K., Milligan, T.G., 1992. Characteristics of suspended particles at an 11-hour anchor station in San Francisco Bay, California. Journal of Geophysical Research 97 (C7), 11,373-11,382.

Kranenburg, C., 1994. The fractal structure of cohesive sediment aggregates. Estuarine, Coastal and Shelf Science 39 (5), 451-460.

Krone, R.B., 1962. Flume studies of the transport of sediment in estuarial shoaling processes. Final Report, Hydraulic Engineering Laboratory and Sanitary Engineering Research Laboratory. University of California, Berkeley.

Krone, R.B., 1963. A study of rheological properties of estuarial sediments. Technical Bulletin No. 7, Committee on Tidal Hydraulics. U.S. Army Engineer Waterways Experiment Station, Vicksburg, MS.

Krone, R.B., 1979. Sedimentation in the San Francisco Bay system. In: Conomos, T.J. (Ed.), San Francisco Bay: An Urbanized Estuary. American Association for the Advancement of Science, pp. 85-96.

Le Hir, P., 1997. Fluid and sediment integrated modeling application to fluid mud flows in estuaries. In: Burt, N., Parker, R., Watts, J. (Eds.), Cohesive Sediments. Wiley, pp. 417-428.

Letter, J.V., 2009. Significance of Probabilistic Parameterization in Cohesive Sediment Bed Exchange. (PhD Thesis) University of Florida, Gainesville.

Manning, A.J., Dyer, K.R., 2007. Mass settling flux of fine sediments in Northern European estuaries: measurements and predictions. Marine Geology 245, 107-122. http://dx. doi.org/10.1016/j.margeo.2007.07.005.

Manning, A.J., Schoellhamer, D.H., 2013. Factors controlling floc settling velocity along a longitudinal estuarine transect, estuary. Marine Geology. http://dx.doi.org/10.1016/ j.margeo.2013.06.018.

Martin, J.L., McCutcheon, S.C., 1998. Hydrodynamics and Transport for Water Quality Modeling. CRC Press.

McAnally, W.H., Mehta, AJ. 2002. Significance of aggregation of fine sediment particles in their deposition. Estuarine, Coastal and Shelf Science 54, 643-653.

Mehta, A.J., 1973. Depositional Behavior of Cohesive Sediments. (PhD Thesis) University of Florida, Gainesville.

Mehta, A.J., Partheniades, E., 1975. An investigation of the depositional properties of flocculated fine sediments. Journal of Hydraulic Research 4, 361-381.

Overbeek, J.T.G., 1952. Kinetics of flocculation. In: Kruyt, H.R. (Ed.), Colloid Science. , vol. 1. Elsevier, pp. 278-300.

Prandle, D., Lane, A., Manning, A.J., 2005. Estuaries are not so unique. Geophysical Research Letters 32. http://dx.doi.org/10.1029/2005GL024797.

Schweim, C., Spork, V., Prochnow, J.V., Köngeter, J., Zhou, J., 2000. Large eddy simulation of a lid-driven rotating annular flume flow. Proceedings of the 4th International Conference on Hydroinformatics. Iowa Institute of Hydraulic Research, Iowa City (CD-ROM).

Shrestha, P.L., Orlob, G.T., 1996. Multiple distribution of cohesive sediments and heavy metals in estuarine systems. Journal of Environmental Engineering 122 (8), 730-740.

Son, M., Hsu, T.-J., 2008. Flocculation model of cohesive sediment using variable fractal dimension. Environmental Fluid Mechanics 8 (1), 55-71.

Soulsby, R.L., Manning, A.J., Spearman, J., Whitehouse, R.J.S., 2013. Settling velocity and mass settling flux of flocculated estuarine sediments. Marine Geology. http://dx.doi. org/10.1016/j.margeo.2013.04.006.

Sumer, B.M., Chua, L.H.C., Cheng, N.-S., Fredsøe, J., 2003. Influence of turbulence on bed load sediment transport. Journal of Hydraulic Engineering 129, 585-596.

Winterwerp, J.C., 1998. A simple model for turbulence induced flocculation of cohesive sediment. Journal of Hydraulic Research 36 (3), 309-326.

Winterwerp, J.C., 2007. On the deposition flux of cohesive sediment. In: Maa, J.P.-Y Sanford, L.P., Schoellhamer, D.H. (Eds.), Estuarine and Coastal Fine Sediment Dynamics. Elsevier, pp. 209-229.

Winterwerp, J.C., van Kesteren, W.G.M., 2004. Introduction to the Physics of Cohesive Sediment in the Marine Environment. Elsevier.

Winterwerp, J.C., Manning, A.J., Martens, C., de Mulder, T., Vanlede, J., 2006. A heuristic formula for turbulence-induced flocculation of cohesive sediment. Estuarine, Coastal and Shelf Science 68, 195-207. 